\title{
Reliability of Portable Spirometry Performed in the Korea National Health and Nutrition Examination Survey Compared to Conventional Spirometry
}

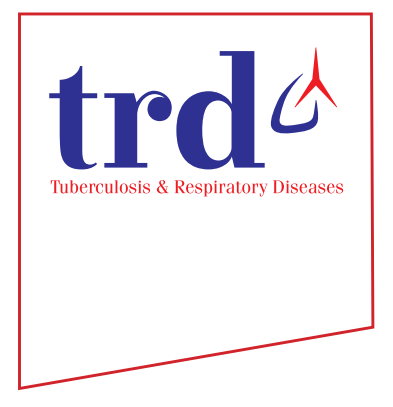

\author{
Hye Jung Park, M.D., Ph.D. ${ }^{1}{ }^{(\mathbb{D}}$, Chin Kook Rhee, M.D., Ph.D. ${ }^{2}$, Kwang Ha Yoo, M.D., Ph.D. ${ }^{3}$ and \\ Yong Bum Park, M.D. ${ }^{4}$ (i) \\ ${ }^{1}$ Department of Internal Medicine, Gangnam Severance Hospital, Yonsei University College of Medicine, Seoul, ${ }^{2}$ Division \\ of Pulmonary and Critical Care Medicine, Department of Internal Medicine, Seoul St. Mary's Hospital, College of Medicine, \\ The Catholic University of Korea, Seoul, ${ }^{3}$ Division of Pulmonary, Allergy and Critical Care Medicine, Department of Internal \\ Medicine, Konkuk University School of Medicine, Seoul, ${ }^{4}$ Division of Pulmonary, Allergy, and Critical Care Medicine, \\ Department of Internal Medicine, Hallym University Kangdong Sacred Heart Hospital, Seoul, Republic of Korea
}

Background: The Korea National Health and Nutrition Examination Survey (KNHANES) is a well-designed survey to collect national data, which many researchers have used for their studies. In KNHANES, although portable spirometry was used, its reliability has not been verified.

Methods: We prospectively enrolled 58 participants from four Korean institutions. The participants were classified into normal pattern, obstructive pattern, and restrictive pattern groups according to their previous spirometry results. Lung function was estimated by conventional spirometry and portable spirometry, and the results were compared.

Results: The intraclass correlation coefficients of forced vital capacity (FVC) (coefficient, 9.993; 95\% confidence interval [CI], 0.988-0.996), forced expiratory volume in 1 second ( $\mathrm{FEV}_{1}$ ) (coefficient, 0.997; 95\% CI, 0.995-0.998), $\mathrm{FEV}_{1} / \mathrm{FVC}$ ratio (coefficient, 0.995; 95\% CI, 0.992-0.997), and forced expiratory flow at 25-75\% (FEF25-75\%; coefficient, 0.991; 95\% CI, 0.984-0.994) were excellent (all $\mathrm{p}<0.001$ ). In the subgroup analysis, the results of the three parameters were similar in all groups. In the overall and subgroup analyses, Pearson's correlation of all the parameters was also excellent in the total (coefficient, 0.986-0.994; $\mathrm{p}<0.001$ ) and subgroup analyses (coefficient, 0.915-0.995; $\mathrm{p}<0.001$ ). In the paired t-test, $\mathrm{FVC}, \mathrm{FEV}_{1} / \mathrm{FVC}$, and FEF25-75\% estimated by the two instruments were statistically different. However, $\mathrm{FEV}_{1}$ was not significantly different.

Conclusion: Lung function estimated by portable spirometry was well-correlated with that estimated by conventional spirometry. Although the values had minimal differences between them, we suggest that the spirometry results from the KNHANES are reliable.

Keywords: Pulmonary Function Test; Reliability; Spirometry

Address for correspondence: Yong Bum Park, M.D.

Division of Pulmonary, Allergy, and Critical Care Medicine, Department of Internal Medicine, Hallym University Kangdong Sacred Heart Hospital, 150 Seongan-ro, Gangdong-gu, Seoul 05355, Republic of Korea

Phone: 82-2-2225-2754, Fax: 82-2-2224-2569, E-mail: bfspark2@gmail.com

Received: Jan. 25, 2021, Revised: Mar. 12, 2021, Accepted: Mar. 24, 2021, Published online: Mar. 24, 2021

(c) It is identical to the Creative Commons Attribution Non-Commercial License (http://creativecommons.org/licenses/by-nc/4.0/). 


\section{Introduction}

The Korea National Health and Nutrition Examination Survey (KNHANES) is a well-designed survey of national data with a complex, multi-stage probability sample extraction ${ }^{1}$. It includes vast amount of data on demographics, underlying diseases, nutritional status, laboratory data, and even lung function. Recently, coronavirus, air pollutants, and climate changes have made respiratory medicine a focus point ${ }^{2-4}$. The KNHANES data have been widely used in researches on various fields including respiratory medicine ${ }^{5-7}$. Several researchers have revealed that data on the prevalence and clinical characteristics of diseases are reliable under the premise that KNHANES represents all Koreans. Using KNHANES, Yoo et $\mathrm{al}^{8}{ }^{3}$ have reported that the prevalence of chronic obstructive pulmonary disease (COPD) estimated by spirometry was $13.4 \%$, and among them, only $2.4 \%$ had been clinically diagnosed with COPD. Additionally, Chung et al. ${ }^{9}$ have shown that the prevalence of a restrictive spirometric pattern was $12.2 \%$.

In the KNHANES, portable spirometry has been used to estimate lung function since July 2016. Portable spirometry is inexpensive, lightweight, and convenient to use, so that it has been used to establish the KNHANES data by conducting it in a moving bus. In the clinical setting, the non-movable conventional spirometry is widely used, so the reliability of the new portable equipment requires verification with clinical and scientific evidence ${ }^{10,11}$. However, whether the portable spirometry can be a substitute to conventional spirometry remains unclear. To accept study results from lung function data from the KNHANES, we need to confirm the reliability of portable spirometry. Thus, we aimed to verify whether data on lung function estimated by portable spirometry obtained through the KNHANES can be reliable.
Table 2. Results of intraclass correlation

\begin{tabular}{|c|c|c|}
\hline \multirow{2}{*}{ Variable } & \multicolumn{2}{|c|}{ Intraclass correlation } \\
\hline & Coefficient (95\% CI) & p-value \\
\hline \multicolumn{3}{|l|}{ Total } \\
\hline FVC & $0.993(0.988-0.996)$ & $<0.001$ \\
\hline $\mathrm{FEV}_{1}$ & $0.997(0.995-0.998)$ & $<0.001$ \\
\hline $\mathrm{FEV}_{1} / \mathrm{FVC}$ ratio & $0.995(0.992-0.997)$ & $<0.001$ \\
\hline FEF25-75\% & $0.991(0.984-0.994)$ & $<0.001$ \\
\hline \multicolumn{3}{|l|}{ Normal pattern } \\
\hline FVC & $0.994(0.986-0.998)$ & $<0.001$ \\
\hline $\mathrm{FEV}_{1}$ & $0.993(0.983-0.997)$ & $<0.001$ \\
\hline $\mathrm{FEV}_{1} / \mathrm{FVC}$ ratio & $0.954(0.885-0.982)$ & $<0.001$ \\
\hline FEF25-75\% & $0.974(0.934-0.990)$ & $<0.001$ \\
\hline \multicolumn{3}{|l|}{ Obstructive pattern } \\
\hline FVC & $0.983(0.958-0.993)$ & $<0.001$ \\
\hline $\mathrm{FEV}_{1}$ & $0.993(0.982-0.997)$ & $<0.001$ \\
\hline $\mathrm{FEV}_{1} / \mathrm{FVC}$ ratio & $0.991(0.979-0.997)$ & $<0.001$ \\
\hline FEF25-75\% & $0.970(0.926-0.988)$ & $<0.001$ \\
\hline \multicolumn{3}{|l|}{ Restrictive pattern } \\
\hline FVC & $0.996(0.990-0.999)$ & $<0.001$ \\
\hline $\mathrm{FEV}_{1}$ & $0.997(0.991-0.999)$ & $<0.001$ \\
\hline $\mathrm{FEV}_{1} / \mathrm{FVC}$ ratio & $0.970(0.918-0.989)$ & $<0.001$ \\
\hline FEF25-75\% & $0.976(0.933-0.991)$ & $<0.001$ \\
\hline
\end{tabular}

CI: confidence interval; FVC: forced vital capacity; $\mathrm{FEV}_{1}$ : forced expiratory volume in one second; FEF25-75\%: forced expiratory flow at $25-75 \%$.

Table 1. Clinical characteristics of the subjects

\begin{tabular}{|c|c|c|c|c|}
\hline Characteristic & $\begin{array}{l}\text { Normal pattern } \\
\quad(n=20)\end{array}$ & $\begin{array}{l}\text { Obstructive pattern } \\
\qquad(\mathrm{n}=21)\end{array}$ & $\begin{array}{c}\text { Restrictive pattern } \\
(\mathrm{n}=17)\end{array}$ & $\begin{array}{c}\text { Total } \\
(n=58)\end{array}$ \\
\hline Male sex & $9(45.0)$ & $17(81.0)$ & $12(70.6)$ & $38(65.5)$ \\
\hline Age, yr & $43.8 \pm 14.2$ & $64.6 \pm 9.0$ & $61.4 \pm 16.2$ & $56.5 \pm 16.0$ \\
\hline \multicolumn{5}{|l|}{ Recent symptom } \\
\hline Cough & $0(0)$ & $4(19.0)$ & $7(41.2)$ & $11(19.0)$ \\
\hline Sputum & $0(0)$ & $4(19.0)$ & $6(35.3)$ & $10(17.2)$ \\
\hline Dyspnea & $0(0)$ & $3(14.3)$ & $8(47.1)$ & $11(19.0)$ \\
\hline \multicolumn{5}{|l|}{ Inhaler medication } \\
\hline Inhaled corticosteroids & $0(0)$ & $12(57.1)$ & $2(11.8)$ & $14(24.1)$ \\
\hline Long-acting $\beta 2$-agonists & $0(0)$ & $19(90.5)$ & $5(29.4)$ & $24(41.4)$ \\
\hline Long-acting muscarinic antagonist & $0(0)$ & $9(42.9)$ & $4(23.5)$ & $13(22.4)$ \\
\hline Short-acting $\beta 2$-agonists & $0(0)$ & $2(9.5)$ & $0(0)$ & $2(3.4)$ \\
\hline
\end{tabular}

Values are presented as number (\%) or mean \pm standard deviation. 


\section{Materials and Methods}

\section{Participants}

We prospectively enrolled 58 participants from four Korean institutions. We included participants who admitted to respiratory clinics of university hospital from August 12, 2020 to November 11, 2020 and who are classified with following subgroups. Participants who cannot conduct spirometry were excluded. The participants were classified into normal pattern, obstructive pattern, and restrictive pattern groups according to their previous spirometry results. The normal pattern group was defined as participants without respiratory symptoms and underlying respiratory diseases. The obstructive pattern group was defined as those with underlying airway diseases including asthma or COPD and with an obstructive pattern in previous spirometry results (forced expiratory volume in 1 second $\left[\mathrm{FEV}_{1}\right] /$ forced vital capacity $[\mathrm{FVC}]$ ratio $\left.<0.7\right)^{12}$. Lastly, the restrictive pattern group consisted of participants with underlying restrictive diseases including interstitial lung diseases

A

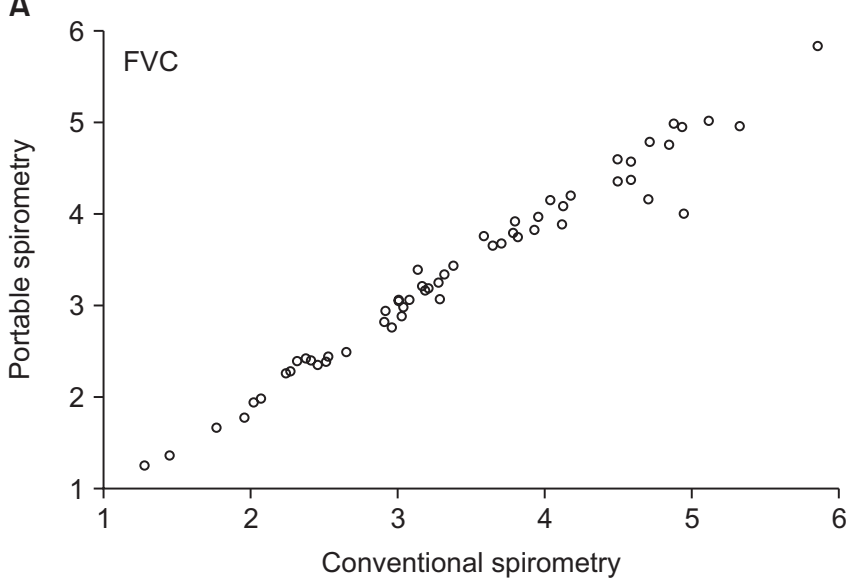

C

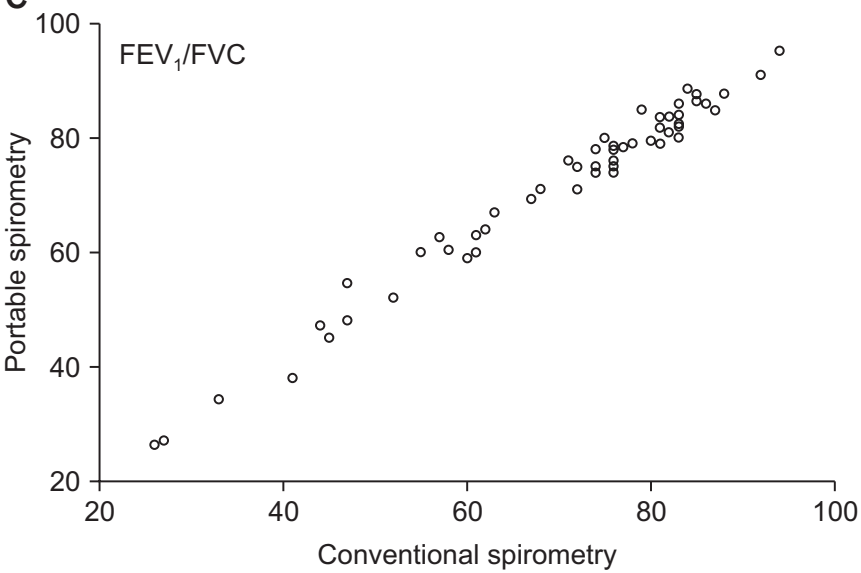

and with a restrictive pattern in previous spirometry results (predicted FVC $<80 \%)^{13}$.

\section{Study design}

The patients were admitted to the hospital and underwent a lung function test using two distinct equipment: conventional spirometry and portable spirometry. They rested at least 1 hour between the two tests. During the rest time, a short survey on demographics, symptoms, and medical history was conducted. The results estimated by the two equipment were compared.

\section{Spirometry}

The four participating institutions utilize the same nonportable conventional spirometry (Carefusion Vmax, SensorMedics, Milan, Italia) that measures lung function, which is widely used in Korea. These four institutions recruited almost same number of subjects evenly for each group. In
B

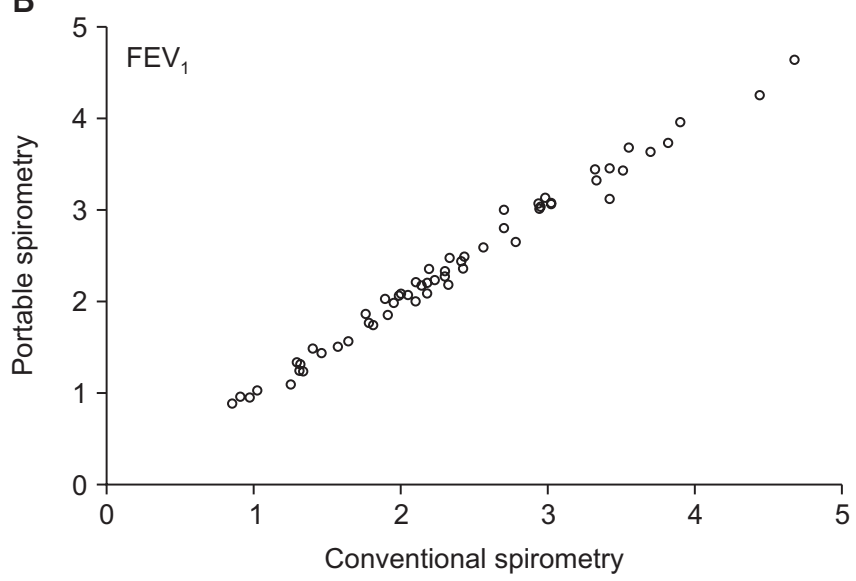

D

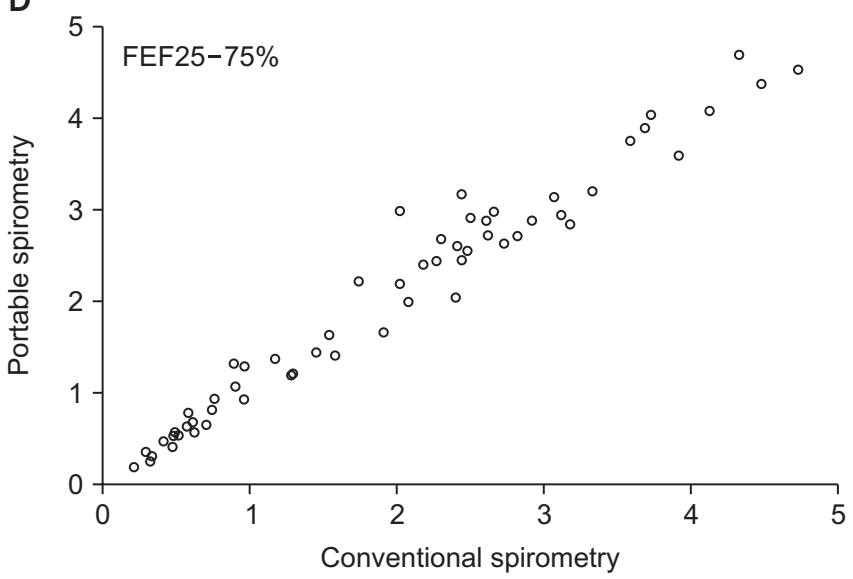

Figure 1. Scatter plot of FVC (A), $\mathrm{FEV}_{1}$ (B), the $\mathrm{FEV}_{1} / \mathrm{FVC}$ ratio (C), and FEF25-75\% (D). FVC: forced vital capacity; $\mathrm{FEV}_{1}$ : forced expiratory volume in 1 second; FEF25-75\%: forced expiratory flow at $25-75 \%$. 
two institutions, portable spirometry was conducted before conventional spirometry. In other two institutions, the order was reversed. Lung function tests were performed according to American Thoracic Society/European Respiratory Society recommendations ${ }^{14}$. Briefly, the following protocol was conducted. The patients were oriented with the test, and they were asked to slightly elevate their heads. They were made to wear a nose clip and a mouthpiece. They inhaled completely and rapidly with a short pause ( $<1$ second), and then exhaled maximally until no more air can be expelled while maintaining an upright posture. The test was repeated as necessary (for a minimum of 3 maneuvers and a maximum of 8 maneuvers). The results met acceptability and reproducibility criteria.

\section{Portable spirometry}

The portable spirometer (Vyntus Spiro, Vyaire Medical $\mathrm{GmbH}$, Hoechberg, Germany) was provided by the department of the KNHANES of the Korean Disease Control and Prevention Agency. Portable spirometry is constituted of lightweight pneumotach handle and long cable which can connect to private computer or notebook. From a single screen, patient data can be entered, flow sensor calibrated, test performed, quality assessment checked, and patient data trended via SentrySuite program. The detectable flow range is about zero to $\pm 16 \mathrm{~L} / \mathrm{sec}$. Resolution is about $1 \mathrm{~mL} / \mathrm{sec}$ and accuracy is about $\pm 5 \%$ at 0.1 to $14 \mathrm{~L} / \mathrm{sec}$. Resistance is $<0.05 \mathrm{kPa} / \mathrm{L} / \mathrm{sec}$ at $10 \mathrm{~L} / \mathrm{sec}$.

\section{Ethics}

This study was approved by the ethics committee, Institutional Review Board (IRB) of four distinct institutions including Gangnam Severance Hospital (number: 3-2020-0264). Patient informed consent was obtained from all the participants.

\section{Statistical analysis}

Results are expressed as mean \pm standard error. Sample size (minimum number, 42) was calculated based on previous study (alpha level, 0.5 and power, 0.95$)^{10}$. The values of $\mathrm{FVC}, \mathrm{FEV}_{1}, \mathrm{FEV}_{1} / \mathrm{FVC}$, and forced expiratory flow at $25-75 \%$ (FEF25-75\%) were followed normal distribution, and it was justified by Shapiro-Wilk test or Kolmogorov-Smirnov test. The intraclass correlation coefficient (ICC) and Pearson's correlation were used to assess the reproducibility and correlation between the results estimated by conventional and portable spirometry. ICC has been widely used to evaluate test-retest reliability. High ICC means high similarity between values form the same group. The significance of the different values estimated by two distinct types of spirometry was assessed using the paired t-test. Bland-Altman analysis was also used to compare two measurements. All statistical analyses were performed using the IBM SPSS version 18.0 (SPSS Inc.,
Chicago, IL, USA). p-values $<0.05$ were considered statistically significant.

\section{Results}

\section{Clinical characteristics of the patients}

The normal pattern $(n=20)$, obstructive pattern $(n=21)$, and restrictive pattern $(\mathrm{n}=17)$ groups were evenly enrolled. Compared to the normal pattern group (male, $45.0 \%$ ), the patients in the obstructive $(81.0 \%)$ and restrictive $(70.6 \%)$ pattern groups were predominantly male. Moreover, the mean age of the obstructive (64.6 years) and restrictive (61.4 years) pattern groups was higher than that of the normal pattern group (43.8 years). The normal pattern group had no respiratory symptoms and no history of inhaler use, in contrast to some patients in the other groups (Table 1).

Table 3. Results of Pearson's correlation

\begin{tabular}{|c|c|c|}
\hline & \multicolumn{2}{|c|}{ Pearson's correlation } \\
\hline & Coefficient & p-value \\
\hline \multicolumn{3}{|l|}{ Total } \\
\hline FVC & 0.986 & $<0.001$ \\
\hline $\mathrm{FEV}_{1}$ & 0.994 & $<0.001$ \\
\hline $\mathrm{FEV}_{1} / \mathrm{FVC}$ ratio & 0.990 & $<0.001$ \\
\hline FEF25-75\% & 0.981 & $<0.001$ \\
\hline \multicolumn{3}{|l|}{ Normal pattern } \\
\hline FVC & 0.990 & $<0.001$ \\
\hline $\mathrm{FEV}_{1}$ & 0.988 & $<0.001$ \\
\hline $\mathrm{FEV}_{1} / \mathrm{FVC}$ ratio & 0.915 & $<0.001$ \\
\hline FEF25-75\% & 0.949 & $<0.001$ \\
\hline \multicolumn{3}{|c|}{ Obstructive pattern } \\
\hline FVC & 0.969 & $<0.001$ \\
\hline $\mathrm{FEV}_{1}$ & 0.989 & $<0.001$ \\
\hline $\mathrm{FEV}_{1} / \mathrm{FVC}$ ratio & 0.984 & $<0.001$ \\
\hline FEF25-75\% & 0.956 & $<0.001$ \\
\hline \multicolumn{3}{|l|}{ Restrictive pattern } \\
\hline FVC & 0.995 & $<0.001$ \\
\hline $\mathrm{FEV}_{1}$ & 0.994 & $<0.001$ \\
\hline $\mathrm{FEV}_{1} / \mathrm{FVC}$ ratio & 0.943 & $<0.001$ \\
\hline FEF25-75\% & 0.953 & $<0.001$ \\
\hline
\end{tabular}

FVC: forced vital capacity; $\mathrm{FEV}_{1}$ : forced expiratory volume in one second; FEF25-75\%: forced expiratory flow at 25-75\%. 


\section{Results of ICC}

Altogether, the ICC of FVC (coefficient, 9.993; 95\% confidence interval [CI], 0.988-0.996), $\mathrm{FEV}_{1}$ (coefficient, 0.997; 95\% CI, 0.995-0.998), and $\mathrm{FEV}_{1} / \mathrm{FVC}$ ratio (coefficient, 0.995; 95\% CI, 0.992-0.997) was excellent (all $\mathrm{p}<0.001$ ). Similarly, in the subgroup analysis, the ICC of FVC, $\mathrm{FEV}_{1}, \mathrm{FEV}_{1} / \mathrm{FVC}$, and FEF25-75\% was also excellent (coefficient, 9.954-9.997; all $\mathrm{p}<0.001$ ) (Table 2). The scattered plot shows the excellent correlation of all parameters (Figure 1).

\section{Results of the Pearson's correlation}

Altogether, the Pearson's correlation of FVC (coefficient, 9.986), $\mathrm{FEV}_{1}$ (coefficient, 0.994), $\mathrm{FEV}_{1} / \mathrm{FVC}$ (coefficient, 0.990), and FEF25-75\% (coefficient, 0.981) were excellent (all $\mathrm{p}<0.001$ ). In the subgroup analysis, Pearson's correlation was also excellent (coefficient, 9.915-9.995; all $\mathrm{p}<0.001$ ) (Table 3).

A

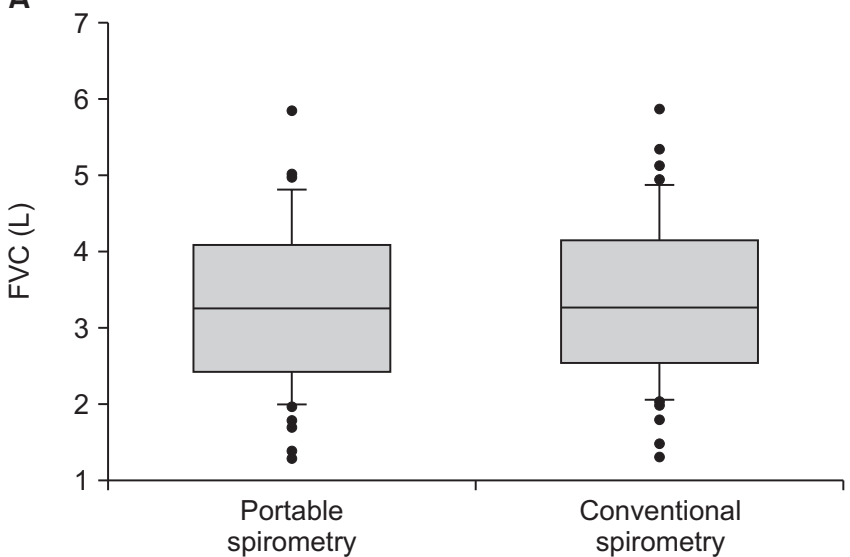

C

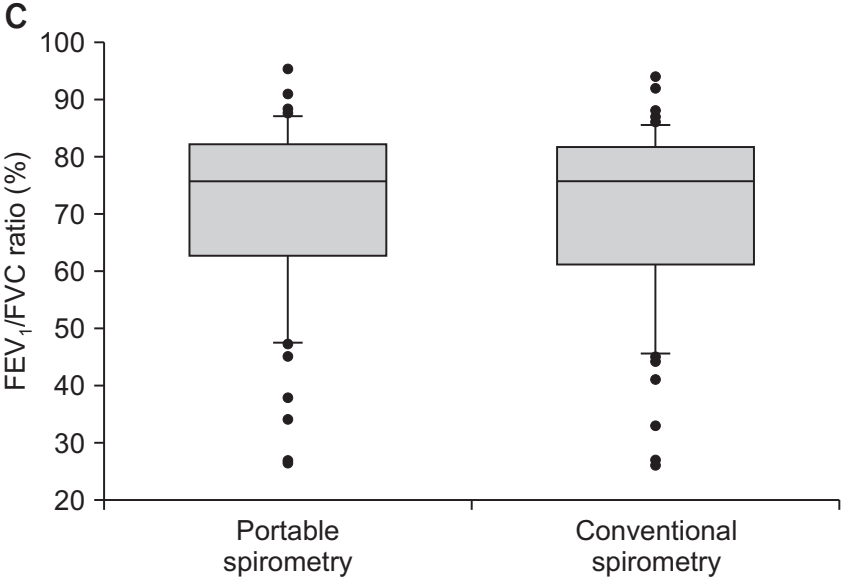

4. Comparison of values measured by conventional and portable spirometry

In the paired t-test, FVC estimated by portable spirometry (3.34 L) was slightly lower than that by conventional spirometry $(3.40 \mathrm{~L}, \mathrm{p}=0.009)$. However, the $\mathrm{FEV}_{1}$ values estimated by portable spirometry $(2.36 \mathrm{~L})$ and conventional spirometry $(2.37 \mathrm{~L})$ were not significantly different $(\mathrm{p}=0.516)$. The $\mathrm{FEV}_{1} /$ FVC ratio estimated by portable spirometry $(71.5 \%)$ was slightly higher than that by conventional spirometry $(70.2 \%$, $\mathrm{p}<0.001$ ). In addition, FEF25-75\% ratio estimated by portable spirometry $(2.03 \mathrm{~L})$ was slightly higher than that by conventional spirometry (1.95, p=0.013) (Figure 2). Bland-Altman plot also showed good correlation of the values estimated between two instruments (Figure 3).

\section{Discussion}

This study showed excellent correlation between lung func-
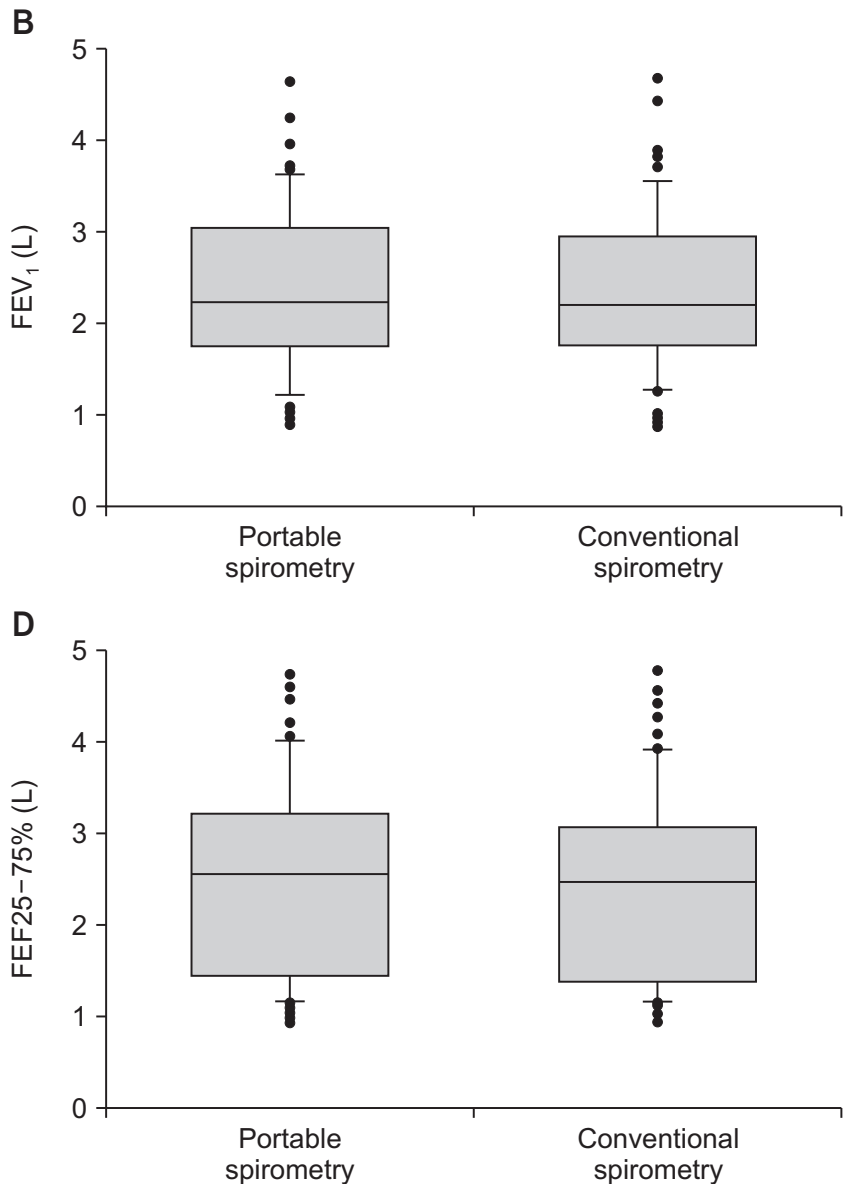

Figure 2. Comparison of FVC (A), FEV 1 (B), the FEV 1 /FVC ratio (C), and FEF25-75\% (D) conducted by portable spirometry and conventional spirometry. FVC: forced vital capacity; $\mathrm{FEV}_{1}$ : forced expiratory volume in 1 second; FEF25-75\%: forced expiratory flow at $25-75 \%$. 

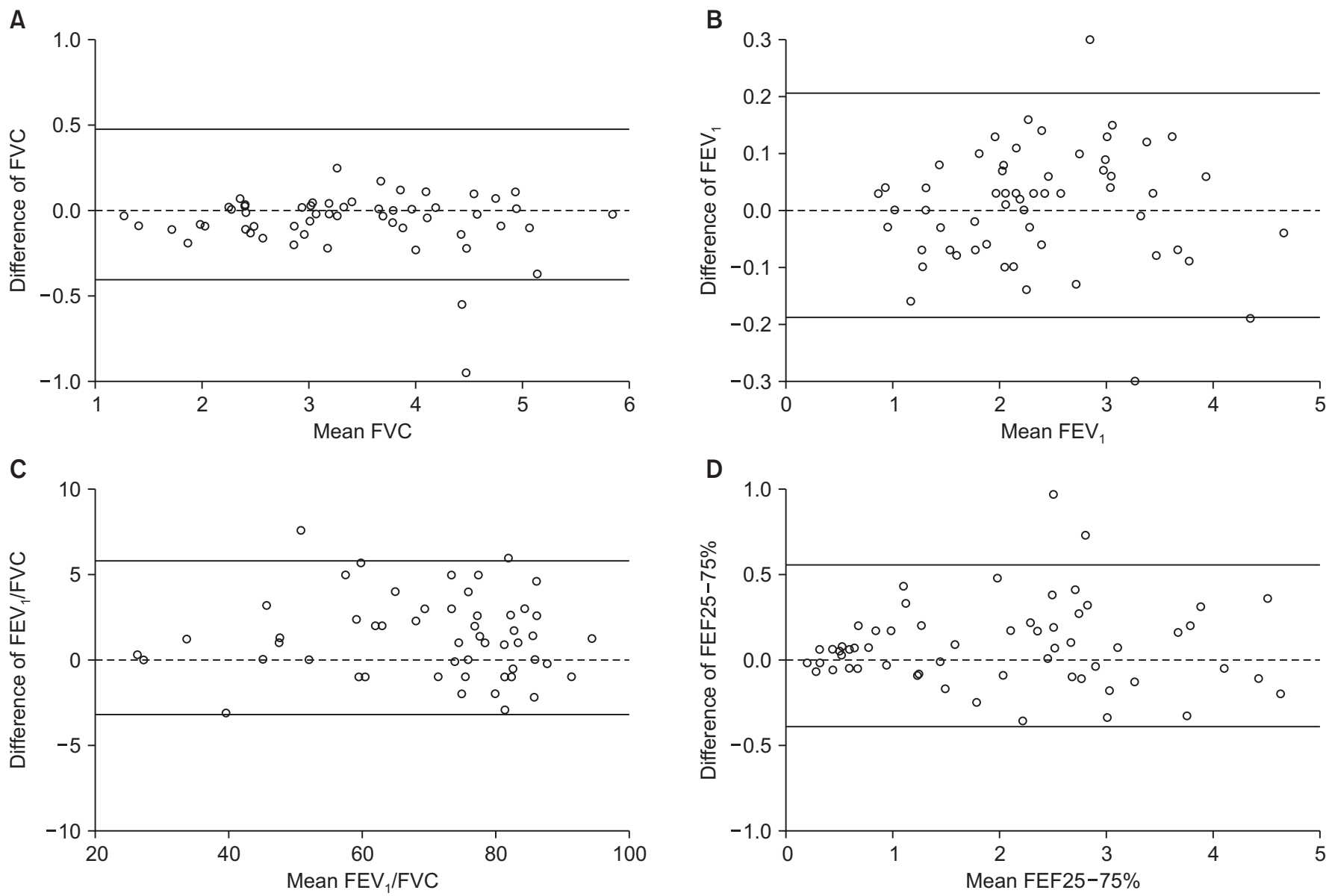

Figure 3. Bland-Altman plot of FVC (A), $\mathrm{FEV}_{1}(\mathrm{~B})$, the $\mathrm{FEV}_{1} / \mathrm{FVC}$ ratio (C), and FEF25-75\% (D). Black line represents $95 \%$ limits of agreement. FVC: forced vital capacity; $\mathrm{FEV}_{1}$ : forced expiratory volume in 1 second; FEF25-75\%: forced expiratory flow at $25-75 \%$.

tion estimated by portable spirometry and conventional spirometry. The representative indicators for reproducibility and reliability of the new method compared to the standardized method, ICC, and Pearson's correlation, were significant in all three important parameters of lung function in total and in the subgroup analysis. Although some values were significantly different in the paired t-test, the differences were not clinically significant. This study also indirectly supported and reenforced reliability of previous clinical study which used lung function data of KNHANES.

Moreover, despite the correlation being generally excellent, the correlation of $\mathrm{FEV}_{1} / \mathrm{FVC}$ measured by ICC and Pearson's correlation was not relatively ideal than that of $\mathrm{FVC}$ and $\mathrm{FEV}_{1}$. The $\mathrm{FEV}_{1} / \mathrm{FVC}$ is a critical indicator in diagnosing COPD. The presence of a post-bronchodilator $\mathrm{FEV}_{1} / \mathrm{FVC}<0.7$ confirms the presence of persistent airflow limitation, which leads to the diagnosis of COPD. The range of $\mathrm{FEV}_{1} / \mathrm{FVC}$ is relatively small, so the $\mathrm{FEV}_{1} / \mathrm{FVC}$ is sensitive to various factors. The value may be changed because of biological variation ${ }^{15,16}$. Therefore, the recent national COPD guidelines suggest that the post- bronchodilator $\mathrm{FEV}_{1} / \mathrm{FVC}$ ratio be confirmed by repeated spirometry on a separate occasion if the value is between 0.6 and $0.8^{17}$. We suggest that a modest correlation of the $\mathrm{FEV}_{1} /$ FVC estimated by portable and conventional spirometry can be explained by insignificant biological variation.

Here, the estimated value of FVC by portable spirometry was significantly lower than that by conventional spirometry. We speculated that this might be lead to relatively low sensitivity to detect extremely low expiratory flow in final exhalation by portable spirometry. The difference of the value was minimal at approximately $60 \mathrm{~mL}$. Additionally, the $\mathrm{FEV}_{1} / \mathrm{FVC}$ measured by portable spirometry was significantly higher than that by conventional spirometry, although the difference was also minimal at approximately $1.3 \%$. Although these minimal differences are not clinically significant, these differences could make the data on the prevalence of restrictive and obstructive diseases inaccurate. Hence, we should consider this significant difference when we interpret the clinical study results of lung function from the KNHANES data.

Recently, a handy spirometer has been developed ${ }^{18,19}$, 
although its compactness can be a disadvantage because frequent movement, crash, and adjustment can lead to several errors and breakdown of this vulnerable equipment. The conventional spirometer is big, non-movable, accurate, and solid. Thus, it is more preferred than the portable one in the clinical setting to obtain accurate information. However, some institutions cannot use conventional spirometry because of space, cost, and convenience. In the KNHANES, portable spirometry was used because this national study should be conducted in a moving bus that travels nationwide. However, studies have been insufficient to confirm the reliability of portable spirometry. We, for the first time, aimed to reveal the reproducibility and reliability of portable spirometry used in KNHANES data.

Our study results suggest that lung function measured by portable spirometry is highly correlated with that by conventional spirometry. If the physicians who use spirometry are highly trained specialists, then we can trust the results of the portable spirometry. In fact, the KNHANES employed specialists to perform the spirometry and have trained them regularly. Additionally, the spirometry results have been periodically verified. Therefore, we suggest that the spirometry results of lung function from the KNHANES are reliable regardless that the data was estimated by portable spirometry.

We attempted to reduce the study bias through the following protocol. First, we evenly included participants with various types of respiratory diseases. Second, we recruited participants from four distinct institutions. Third, we used three analytic methods (ICC, Pearson's coefficient, and paired $\mathrm{t}$-test) to define reliability ${ }^{20}$. Nonetheless, this study has some limitations. First, this study had a relatively small population, so further studies with a larger sample size will more strongly support our hypothesis. Second, we did not analyze postbronchodilator lung function parameters. Third, we did not reveal the reliability of physicians who were engaged in the KNHANES. Thus, further extended studies will be helpful to re-confirm whether the lung function data of the KNHANES is reliable.

Lung function estimated by portable spirometry is wellcorrelated with that estimated by conventional spirometry. However, the values of $\mathrm{FVC}, \mathrm{FEV}_{1} / \mathrm{FVC}$, and FEF25-75\% estimated using two types of spirometry have a small difference. We should consider this significant difference when we interpret the clinical study results of lung function contained in the KNHANES data. Generally, we suggest that the spirometry results contained in the KNHANES is reliable.

\section{Authors' Contributions}

Conceptualization: Park YB. Methodology: Park HJ, Rhee CK, Yoo KH, Park YB. Software: Park HJ, Rhee CK, Yoo KH, Park YB. Validation: Park HJ, Rhee CK, Yoo KH, Park YB. Investigation: Park HJ, Rhee CK, Yoo KH, Park YB. Writing - original draft preparation: Park HJ. Writing - review and editing: Park HJ, Park YB. Approval of final manuscript: all authors.

\section{Conflicts of Interest}

Chin Kook Rhee serves as deputy editor of the Tuberculosis of Respiratory Diseases, but has no role in the decision to publish this article. All remaining authors have declared no conflicts of interest.

\section{Funding}

This work was supported by the Research Program funded by the Korea Centers for Disease Control and Prevention (fund code: 2020-E3405-00).

\section{References}

1. Kim Y, Park S, Kim NS, Lee BK. Inappropriate survey design analysis of the Korean National Health and Nutrition Examination Survey may produce biased results. J Prev Med Public Health 2013;46:96-104.

2. Han H, Oh EY, Lee JH, Park JW, Park HJ. Effects of particulate matter 10 inhalation on lung tissue RNA expression in a murine model. Tuberc Respir Dis 2021;84:55-66.

3. Kim SY, Kim E, Kim WJ. Health effects of ozone on respiratory diseases. Tuberc Respir Dis 2020;83(Suppl 1):S6-11.

4. Jirjees FJ, Dallal Bashi YH, Al-Obaidi HJ. COVID-19 death and BCG vaccination programs worldwide. Tuberc Respir Dis 2021;84:13-21.

5. Kwon DS, Kim TH, Byun MK, Kim HJ, Lee HS, Park HJ, et al. Positive effects of the national cigarette price increase policy on smoking cessation in South Korea. Tuberc Respir Dis 2020;83:71-80.

6. Park YS, Park S, Lee CH. The attributable risk of smoking on all-cause mortality in Korean: a study using KNHANES IV-VI (2007-2015) with mortality data. Tuberc Respir Dis 2020;83:268-75.

7. Park HJ, Byun MK, Kim HJ, Kim JY, Kim YI, Yoo KH, et al. Dietary vitamin $\mathrm{C}$ intake protects against COPD: the Korea National Health and Nutrition Examination Survey in 2012. Int J Chron Obstruct Pulmon Dis 2016;11:2721-8.

8. Yoo KH, Kim YS, Sheen SS, Park JH, Hwang YI, Kim SH, et al Prevalence of chronic obstructive pulmonary disease in Korea: the fourth Korean National Health and Nutrition Examination Survey, 2008. Respirology 2011;16:659-65.

9. Chung SJ, Kim HI, Yang B, Kim T, Sim YS, Kang HK, et al. Impact of the severity of restrictive spirometric pattern on nutrition, physical activity, and quality of life: results from a nationally representative database. Sci Rep 2020;10:19672. 
10. Izbicki G, Abboud S, Jordan P, Perruchoud AP, Bolliger CT. A comparison of a new transtelephonic portable spirometer with a laboratory spirometer. Eur Respir J 1999;14:209-13.

11. Liistro G, Vanwelde C, Vincken W, Vandevoorde J, Verleden G, Buffels J, et al. Technical and functional assessment of 10 office spirometers: a multicenter comparative study. Chest 2006;130:657-65.

12. Park YB, Rhee CK, Yoon HK, Oh YM, Lim SY, Lee JH, et al. Revised (2018) COPD clinical practice guideline of the Korean Academy of Tuberculosis and Respiratory Disease: a summary. Tuberc Respir Dis 2018;81:261-73.

13. Lee SH, Yeo Y, Kim TH, Lee HL, Lee JH, Park YB, et al. Korean guidelines for diagnosis and management of interstitial lung diseases: part 2. idiopathic pulmonary fibrosis. Tuberc Respir Dis 2019;82:102-17.

14. Miller MR, Hankinson J, Brusasco V, Burgos F, Casaburi R, Coates A, et al. Standardisation of spirometry. Eur Respir J 2005;26:319-38.

15. Aaron SD, Tan WC, Bourbeau J, Sin DD, Loves RH, MacNeil J, et al. Diagnostic instability and reversals of chronic obstructive pulmonary disease diagnosis in individuals with mild to moderate airflow obstruction. Am J Respir Crit Care Med
2017;196:306-14

16. Schermer TR, Robberts B, Crockett AJ, Thoonen BP, Lucas A, Grootens J, et al. Should the diagnosis of COPD be based on a single spirometry test? NPJ Prim Care Respir Med 2016;26:16059.

17. Singh D, Agusti A, Anzueto A, Barnes PJ, Bourbeau J, Celli $\mathrm{BR}$, et al. Global strategy for the diagnosis, management, and prevention of chronic obstructive lung disease: the GOLD science committee report 2019. Eur Respir J 2019;53:1900164.

18. Ramos Hernandez C, Nunez Fernandez M, Pallares Sanmartin A, Mouronte Roibas C, Cerdeira Dominguez L, Botana Rial MI, et al. Validation of the portable air-smart spirometer. PLoS One 2018;13:e0192789.

19. Kupczyk M, Hofman A, Koltowski L, Kuna P, Lukaszyk M, Buczylko K, et al. Home self-monitoring in patients with asthma using a mobile spirometry system. J Asthma 2021;58:50511.

20. Yang SY, Kim YH, Byun MK, Kim HJ, Ahn CM, Kim SH, et al. Repeated measurement of fractional exhaled nitric oxide is not essential for asthma screening. J Investig Allergol Clin Immunol 2018;28:98-105. 